\title{
Risk, Human Rights and the Management of a Serious Sex Of- fender ${ }^{*}$
}

Noel Whitty

\begin{abstract}
Risk and human rights discourses have become dominant features of the UK criminal justice arena. However, there has been little critical scrutiny of the ways in which these discourses relate to each other. In this article, I focus on different accounts of the case of Anthony Rice, a 48-year old ex-offender who committed a murder in August 2005 whilst under the joint supervision of English probation and police services. Drawing upon official reviews by the Inspectorate of Probation and the UK Parliament Joint Committee on Human Rights, as well as media coverage, I use the Rice case to problematise some common assumptions about the relationship between riske and buman rights.
\end{abstract}

Keywords: Risk Assessment; Risk. Management; Human Rights; Sex Offenders

\section{Introduction: The Rice case}

On 17 August 2005, a 40-year old woman, Naomi Bryant was murdered at her home in Hampshire, England. Her attacker, Anthony Rice, had been freed from prison in November 2004 after serving 15 years of a 'discretionary life sentence' for an attempted rape. Upon his release, he was subject to supervision by Hampshire Police and Hampshire Probation Service under what is termed Multi-Agency Public Protection Arrangements (MAPPA). Formally established by legislation in 2000, this inter-agency system for risk management of serious violent and sex offenders in England and Wales requires local Multi-Agency Public Protection Panels (MAPPP) to convene, share all relevant information, and monitor individual risk assessment and management plans for the most serious offenders resettling in their area (Kemshall et al. 2005). ${ }^{1}$ At the time of the murder, under the terms of his MAPPP management plan, Rice was classified as at 'high risk' of reoffending and was residing under curfew and other conditions at a charity-run hostel. In October 2005, after Rice was convicted of the Bryant murder and sentenced to a minimum of 25 years imprisonment, an official inquiry was launched by the Inspectorate of Probation into the failures in the system of supervision in Rice's case.

The Inspectorate's Report, published in May 2006, identified a 'cumulative failure' in the management of Rice while he was in prison and also after release. It highlighted a

* My thanks to Thérèse Murphy, Susanne Karstedt and Bettina Lange for their helpful comments.

1 In 2005-06, there was a total of 47,653 MAPPA offenders in the community, out of which $1278(3 \%)$ required the highest Level 3 form of MAPPP supervision (see generally Wood 2006). 
series of 'mistakes, misjudgements and miscommunications' (2006: 2) by all the main actors involved with the case - including different prison staff, psychologists, Parole Board members, probation staff and police officers. In particular, the Inspectorate noted (a) the general failure to take account of Rice's previous sexual offences against children in the 1970s; (b) inadequate risk assessment processes and record-keeping; (c) the insufficient evidence before the Parole Board when it decided that Rice be moved to open prison conditions in 2002 and then released under supervision in 2004; (d) the lack of effective communication between the relevant MAPPA actors; and (e) the insufficient monitoring by probation and police of Rice's compliance with the conditions of his release (for example, the ban on alcohol usage and association with lone women). Throughout the Report, the Inspectorate also drew specific attention to what it identified as a key factor in the incorrect management of the public risk posed by Anthony Rice 'human rights considerations':

It was also from 2001 that in our view the people managing this case started to allow its public protection considerations to be undermined by its human rights considerations, as these required increasing attention from all involved, especially as the prisoner was legally represented (2006: 5).

Subsequent media coverage, and official commentary, focused almost exclusively on the alleged causal role of the Human Rights Act (HRA) 1998 in the death of Naomi Bryant. Most notably, the Prime Minister, Tony Blair, cited the Bryant murder as part of his general attack on the alleged effects of European Convention on Human Rights (ECHR) jurisprudence on UK law and pledged to ensure that 'the law-abiding majority can live without fear' (Observer, 14 May 2006). More specifically, the Secretary of State for Constitutional Affairs asserted that the Parole Board and Probation Service 'were concerned about legal action against them on human rights grounds ... In [the Rice] case they came to the wrong conclusion, and prioritised his right to liberty over public protection' (Falconer 2007). As a result of the ensuing political controversy, the UK Parliament Joint Committee on Human Rights conducted its own investigation into the Rice case. It flatly rejected the official version of events and found that there was no factual evidence of a 'clear causal connection between any interpretation or application of the HRA [1998] and the death of Naomi Bryant' (JCHR 2006: 15). Instead, it directly condemned government ministers for actively encouraging public misperceptions about the Human Rights Act and for using rights discourse as 'a convenient scapegoat for unrelated administrative failings within Government'. It also claimed that the Inspectorate's Report was 'the product of a misunderstanding of the HRA' because it maintained:

a dubious antithesis between human rights considerations and public protection considerations, which does not acknowledge that, properly understood, public protection forms a crucial part of an overall human rights perspective in cases such as those of Anthony Rice (JCHR 2006: 16).

In this article, I use the Rice case to analyse risk and human rights discourses in the context of sex offender management. These discourses tend to be represented in oppositional terms. UK legal and criminological scholarship help to constitute and reinforce this framing: for the most part, risk discourses have been used by criminologists and not by lawyers; equally, although human rights has featured prominently in the work of lawyers, it is rarely discussed in criminology. My aim is to highlight the need for a combined 'risk and 
rights' stream of academic enquiry which acknowledges the co-existence of different risk and rights discourses (Murphy and Whitty 2007; Sparks 2001).

Specifically, I argue for the recognition of different types of risk and rights knowledges, and of the fact that these operate in different institutional and cultural settings, and can overlap in unpredictable ways. I draw upon the following three themes to analyse characteristics of the Rice case: (1) the social construction of risk in offender management; (2) how organisations 'frame' questions of risk and rights compliance; and (3) the diversity of understandings and representations of 'human rights'.

\section{The Social Construction of Risk in Offender Management}

Practices of risk assessment are most often represented as requiring expert scientific processes of judgement. As Lupton has highlighted, techno-scientific approaches aim to identify, map, predict and regulate different types of risk according to allegedly objective criteria, and do not acknowledge the influence of socio-political choice on the technologies of risk (1999: 2). In contrast, critical scholarship on risk has argued for analyses that recognise the variability of risk technologies and knowledges (for example, in relation to gender (Hannah-Moffat 2005)), as well as how different risks are socially constructed (e.g., Mythen and Walklate 2006; Levi 2000). Sparks, furthermore, has argued for particular scrutiny of the 'ways in which risks are communicated and how they are politicised' (2000: 132). In the criminal justice arena, and especially in relation to the MAPPA framework, the impact of risk-based thinking has been especially significant. However, as Kemshall has argued, the 'use of subjective and professional judgements alongside of, and at times, in place of actuarial tools' remains, as well as the continued 'role of professional values and occupational culture in risk practice' (2003: 96). For example, the foregrounding of even apparently 'rational' criteria (such as statistical correlations or previous convictions) may be very misleading as to the actual nature of risk governance. First, as Moore and Valverde point out, the apparent privileging of expert knowledges and quantifiable formats does not mean that 'myths, symbols and non-rational fears' may not also shape the construction of certain 'risks' (2000: 515). Secondly, the aura of expertise surrounding the methods of risk assessment may hide a more mundane reality: that is, 'risk calculations and predictions are in fact often carried out by non-scientific personnel using very subjective tools' (Moore and Valverde 2000: 521).

In the accounts of the Rice case, a range of failings can be identified to substantiate challenges to the representation of risk assessment/management as inevitably expert, actuarial and deterministic. For example, the Inspectorate's Report reveals that risk assessments were conducted by the Prison Service in the absence of Rice's full criminal record (which was easily accessible on the Police National Computer system); the recommended use of the structured risk assessment tool, Offender Assessment System 
(OASys), ${ }^{2}$ never occurred prior to his release with the result that Rice (a 'high risk' offender) was permitted to reside in a hostel with inadequate security arrangements; and the personnel attending MAPPA meetings supervised Rice's management plan without having full knowledge of, or attempting to monitor, key risk factors (such as his alcohol usage).

Poor communication and resource limits were recognised by the Inspectorate as key factors in the overall failure in the risk management of Rice. However, what is also plainly confirmed in this case is the subjective and arbitrary use of the two main risk tools: OASys and Risk Matrix 2000. ${ }^{3}$ Moreover, where risk information was available, the extent to which it was actually relied upon in the practices of prison, probation and police personnel was also found to be very variable. For example, the police completed a Risk Matrix 2000 assessment which took account of Rice's sexual offending but failed to take account of his violent offending; information which would have raised his status from 'high' to 'very high risk.' There was also no record of this assessment actually being shared with the MAPPA meeting as required by protocol. Perhaps more significantly, the Rice case confirms research which has indicated that approximately 70 per cent of OASys assessments may be incomplete or not completed properly by probation staff (Kemshall et al. 2005: 17). For example, Rice's supervising probation officer never updated the original OASys assessment (which would have required re-inputting the data) with the result that Rice's management plan was based on incomplete information. The influence of socio-cultural and organisational factors may, therefore, be the key to understanding the exact nature and effectiveness of a particular risk technology. Confirmation of this can be found in a BBC radio documentary on the working of MAPPA and the use of OASys. When asked whether computer software was the reason for incomplete OASys assessments, Mike McLelland (the leader of the Probation Officers' national union, NAPO) replied:

My criticism of it would be that it's too long, it's too unwieldy, it's difficult to use. At the moment it's an electronic document, if you print it off, depending on how much you've written in it, you're going to get the document that's somewhere between 35 and 42 pages long. It's only when you finish the first thirteen sections that you get into the risk of harm screening and then the full risk of assessment and I think to be perfectly fair, by the time people have got through thirteen sections they're just getting a little jaded with this tool that they're having to fill in. I think there's still a considerable degree of resistance to using it (BBC 2006: 11).

Yet, even if an OASys assessment is complete and accurate, the extent to which it actually forms part of the MAPPA decision-making process needs also to be scrutinised. As the Inspectorate's Report indicates, the minutes of the Hampshire MAPPA meeting held to

2 OASys is used by the Probation and Prison Services, and is designed to identify previous patterns of behaviour and warning signs, to assess the risk of harm, and to highlight the protective factors which could reduce the risk posed.

3 Risk Matrix 2000 is used by the Police Service in England and Wales and is designed to assess violent and sex offenders. 
discuss Anthony Rice's management plan are 'brief, and provide little evidence of a detailed and structured risk assessment':

On 23rd November a MAPPA meeting was held. The OASys completed by London had arrived in Hampshire since the previous meeting and was in the Probation file. This assessment could have made a valuable contribution to the MAPPA meeting's understanding of Anthony Rice, but we can find no evidence that the MAPPA received or made use of it (2006: 39-40).

In conclusion, the importance of unpacking the social construction of risk is clearly demonstrated by the sequence of failures in the assessment and management of Anthony Rice. Also, even if there were some exceptional factors in this particular case (such as the then-ongoing shift from handwritten to electronic information systems), assumptions about the central and determinative role of risk technologies in serious sex offender management need to be treated with caution. Theoretical and empirical scrutiny is needed of the precise role and effects of different risk tools, and of the actual usage of risk knowledges by different criminal justice actors. In addition, placing the emphasis on social constructionist accounts of risk will more accurately capture the wider political implications of serious sex offender management where, for example, the organisational consequences of a particular risk classification ('high risk' rather than 'medium risk' offenders) can be very undesirable in terms of the increased workloads placed on personnel and the allocation of limited resources (Kemshall and Maguire 2001: 250).

\section{How Organisations Frame Questions of Risk and Rights Compliance}

The second issue on which the Rice case throws very interesting light is how criminal justice organisations attempt to comply with different risk-based and rights-based obligations or expectations. In the UK, risk compliance is a particularly complex question as public administration is increasingly organised and regulated around the concept of 'organisational risk' (Hutter 2006; Hood et al. 2004; Fisher 2003). This has resulted in a range of internal and external actors (especially the UK Treasury) monitoring how organisations assess and manage their own 'business risk register', with potential risks categorised under general headings such as operational, financial, reputational or legal risk.

The National Probation Service Circular PC02/2007, Risk Management Standard Format is an example of the type of documentation and terminology now used in the criminal justice sector. It places the onus on managers to monitor organisational risk in the following terms:

Organisations are increasingly being required to demonstrate effective corporate governance and internal control. At the same time there is also a primary objective to deliver performance. As we deal with risks on a daily basis, it is very important that the arrangements and processes for managing risk are well understood. For example the following types of action can be taken to respond to risk situation[s] on a daily basis: Transfer some aspect of the risk; Tolerate the risk; Treat the risk; Terminate the risk. All probation areas are expected to address risk issues because identifying the sources of risk and the area of impact on the business of the organisation will contribute to the effective management of the risk (2007: 2).

The Circular goes on to create a scale for identifying the likelihood of risks, ranging from 'very low' (less than $5 \%$ chance of occurrence) to 'very high' (more than $80 \%$ chance). It 
then provides guidance on assessing the impact of particular occurrences at different organisational levels under the headings of: public protection (exposing the public to injury or loss of life); financial (overspends from under $f^{2}$ million to over $f_{2} 5$ million); reputation (from public criticism up to ministerial resignation); and delivery (failure to achieve objectives). Templates of risk registers are also included in the Circular, along with very basic notes on how to complete each section. Of course, the crucial question is whether - and, if so, how - this general guidance to all 'business risk managers' in the Probation Service translates into day-to-day decisions and practices. Practically nothing is known about this aspect of governance due both to the absence of published empirical research and, one can assume, particular sensitivity about the political (and, in some instances, legal) implications of detailed revelations.

Allied with this new focus on organisational risk in the public sector, the functional roles of traditional criminal justice actors - such as the Parole Board - have also been redefined by their increasing reliance on new technologies of individual risk assessment and management. There is an ongoing shift from the use of professional clinical diagnosis towards an increased role for actuarial risk tools when predicting the risk of (re-)offending or endangering public safety. This is being reinforced by the increasing number of statutes and administrative practices foregrounding 'risk of harm' tests within the UK criminal justice and welfare systems (Kemshall 2003). ${ }^{4}$

In the specific context of sex offender management, these different risk-based obligations mean that a range of organisations (parole boards, police forces, prison and probation services, housing authorities, etc) are now closely connected in a network of risk compliance under MAPPA. Each organisation is expected both to satisfy a range of legal obligations to protect public safety and to comply with public sector governance rules to manage its own 'risk register'. These tasks require organisations to take account of both traditional legal rules (statutes, caselaw) and an increasing range of non-legal rules and standards (Treasury guidelines, Ministry of Justice circulars, etc) (Fisher 2003). The emphasis is placed on constant assessing, managing and monitoring of a range of potential risks - and assumes, in each context, that the relevant risk knowledge (psychiatric, legal, financial, etc) is both available and accurate. Effective risk management also places a heavy emphasis on 'defensibility': that is, ensuring adequate lines of responsibility/blame in the event of an undesirable outcome. Not surprisingly, in the field of serious sex offender management, the degree of organisational exposure to potential risks - due to the threat to public safety, the history of media coverage and political fallout (Bell 2002) - is very high.

The second main type of regulatory demand that needs to be considered is the rights-based one. All public sector organisations (and private companies who perform a 'public function' such as prison management) must comply with the provisions of the HRA 1998. In theory, this means that each 'public authority' in the UK must fulfil the legal obligation to respect ECHR rights in the performance of its duties (Lester and Pan-

4 The most conspicuous evidence of this is Scotland's Risk Management Authority, which has the statutory purpose of 'ensuring the effective assessment and minimisation of risk' (see Criminal Justice (Scotland) Act 2003). 
nick 2004). However, what this means in practice remains largely unexplored as there is very little empirical legal scholarship on the impact of human rights in the UK. Neither the initiation of rights claims nor the implementation of rights norms has been much studied (Halliday and Schmidt 2004). The information that is available on public sector responses to the HRA 1998 portrays a mixed picture. It shows variable patterns of legal knowledge, political commitment, exercise of professional judgment, allocation of required resources and fear of sanction within public authorities (Clements and Thomas 2005). Furthermore, where there is an official organisational response to the HRA 1998, 'defensive compliance' may be prioritised, rather than proactively seeking to use rights as a normative source in policy and decision-making processes.

When one focuses on the specific contexts of prisoner release and offender management, as in the Rice case, some further distinctions must be made between organisational responses to the HRA 1998. This is because the legal roles of the Parole Board and of the organisations involved in MAPPA (such as police and probation services) are formally and substantively very different. While ECHR caselaw has been the decisive influence on UK statutory reforms which have expanded the role and procedures of the $\mathrm{Pa}$ role Board (for example, all prisoners sentenced to life imprisonment now have a right to legal representation in hearings), there is no evidence to indicate that the practices of organisations involved in MAPPA have been affected by human rights law (or rights consciousness) to any similar extent (Kemshall et al. 2005).

In light of the above discussion on how organisations frame their risk-based and rights-based obligations, the factual details in the Inspectorate's Report on the decisions, actions and failures in the management of Anthony Rice are revealing. For example, from an organisational risk perspective, one would have expected to find clear evidence in the monitoring of Rice (a 'high risk' offender) to support Sparks' general observation that '[s]ometimes the political risks become so large that almost any risk-taking by [criminal justice] practitioners comes to seem unaffordably foolhardy' (2000: 131). Yet, the very opposite seems the case. In particular, the decisions and actions taken in relation to Rice's supervision after release (for example, never questioning the security arrangements in the hostel or challenging his known alcohol usage) betray no heightened risk consciousness on the part of the relevant MAPPA actors. Other reasons, of course, may explain this. For example, the high numbers of offenders subject to probation and MAPPA supervision, and the related lack of necessary personnel and resources, may mean that 'management' of (even 'very high risk') individuals is often a cursory process. ${ }^{5}$ Kemshall has highlighted the police perception that MAPPA can absorb disproportionate resources, does not reduce offending propensity and is unpopular with the public (2003: 98). Another key reason may be the apparent absence of effective communication between different (hierarchal) criminal justice organisations, despite the 'inter-agency' structure of MAPPA. Indeed, misunderstanding, lack of communication and blurred lines of responsibility, as evident from the Inspectorate's comments on the flawed choice of accommodation for Rice, may be a consequence of the MAPPA framework: 
Probation staff and police believed that Elderfield [hostel] would physically check that Anthony Rice was in the hostel during his curfew time ... However, this hostel did not have the necessary security systems to allow them to do so. Elderfield staff, for their part, assumed that their systems were understood, as they had accommodated other high risk offenders in the past (2006: 41).

Two general conclusions on organisational risk management can be drawn from the Inspectorate's Report. First, in analysing the extent of organisational risk compliance by individual MAPPA actors, it may be difficult to identify the exact nature of governing relationships amongst the range of organisations and personnel. Furthermore, despite all the official documentation and rhetoric surrounding internal and external audits of risk compliance, the key question to be answered remains: have government departments and public sector organisations actually bought into risk based initiatives and, if so, to what extent (Hutter 2006: 220)? In the context of MAPPA, analysis is further complicated by the fact that actors' 'management' of organisational risks (such as public protection or reputation) can be closely connected to, and even determined by, individual offender risk management. Yet contemporary police supervision, for example, even for those classed at 'high risk' of re-offending can be minimal. As one police officer in an area of Northern England revealed to a journalist: '[b]eing considered high risk sounds serious, doesn't it? In reality, it means I spend an hour in his flat every three to six months chatting to him about what he's been up to' (Observer, 7 January 2007).

Secondly, as Kemshall and Maguire noted in an earlier study of MAPPA (2001: 253), and as the general reluctance of probation officers to use the OASys tool suggests, the actual practice of offender risk assessment can be crude, partial and technologicallyunsophisticated. The construction of risk may also not depend on a single distinct knowledge base but, more typically, combine some mixture of actuarial, clinical, professional and common sense views. There is also no guarantee, as the Rice case demonstrates, that risk management personnel will always avail of, and act upon, the risk information that has been collected. Black's general observation that in the current climate the 'rhetoric of "risk management" and "risk-based" approaches combines a sense of strategy and control in a way which is politically compelling', may thus be entirely accurate (2005: 19).

\section{The Diversity of Understandings and Representations of Human Rights}

Turning now to an analysis of the Rice case from a human rights-based perspective, some interesting questions are raised about both the practical and symbolic impact of the HRA 1998. In the Inspectorate's Report, there are repeated references to the challenges posed by 'human rights considerations' and lawyers; in particular, the alleged negative impact of these legal forces on the commitment to public protection:

At an oral hearing of a panel of the Parole Board the prisoner will have, as Anthony Rice had in 2004, counsel to represent him. The staff representing the Secretary of State, and the Parole Board members, have to apply themselves to testing 'whether the Lifer's level of risk to the life and limb of others is considered to be more than minimal.' In this context it is a challenging task for people who are charged with managing offenders effectively to ensure that public protection considerations are not undermined by the human rights considerations (2006: 57). 
Other references in the Report state that 'an increasing focus on [Rice's] human rights rather than public protection' developed when he was being held in open prison prior to his release (2006: 72); and that MAPPA meetings faced potential legal challenges from Rice's solicitor on the grounds that the original licence conditions (curfew hours, a geographical containment zone, no alcohol usage nor contact with lone females) 'contravened [Rice's] human rights' (2006: 63).

The question raised by this criticism is whether MAPPA personnel did believe that 'human rights' could 'trump' public protection concerns in the ways outlined. The Inspectorate's Report supports this interpretation by asserting that the conduct of risk assessments, and the appropriate management of Rice, were hampered by an overriding attention to human rights. One explicit example is the statement that 'we find it regrettable that attention to effectiveness and enforceability [of Rice's release conditions] was undermined by the attention devoted to issues of lawfulness and proportionality' (2006: 37). If this claim is correct, however, it would have a significance far beyond the immediate search for the failings in Rice's supervision. Contrary to literature which emphasises dominant risk control models in the field of criminal justice, it would provide concrete evidence that human rights (law) can play a normative role in the calculations of risk management (Zedner 2006). Worryingly, however, despite its reference to the text of the ECHR Article 8 right to privacy, the Inspectorate's account suggests that the proper application of human rights law (e.g., the proportionality test) required a lesser regard for public protection. ${ }^{6}$ In other words, a stark dichotomy, rather than a balance, was constructed between risk (of harm) and rights discourses.

The core problem, however, with the Inspectorate's representation of human rights is that there is no evidence provided in the Report to substantiate the claims made. This is confirmed by the UK Parliament Joint Committee on Human Rights (JCHR), which published its findings on the Rice case in November 2006. It concluded that a series of errors and misjudgements led to the cumulative failure in the case, but it was unable to find 'any concrete evidence in the Report itself that any decision concerning the release or management of Anthony Rice was affected in any way by human rights considerations being given precedence over public protection' (JCHR 2006: 14). For example, the Parole Board might have reached a different decision on release if the information on Rice's previous convictions had not been withheld from it. Similarly, it was lack of information and misunderstandings which led MAPPA actors to select the wrong hostel for Rice, and then inadequately supervise him when in the community. Intriguingly, when asked to supply evidence to explain why the Report blamed human rights for the failures in the case, the Inspectorate submitted a letter to the JCHR containing two admissions. First, it stated that it "was a huge distortion of our findings when some newspapers said that Rice was released in order to "meet his human rights". Secondly, it described the rights awareness amongst probation staff as having a 'distracting' effect and operating in 'subtle' ways:

6 Article 8(1) of the ECHR states that everyone has a right to privacy. Article 8(2), however, permits the lawful and proportionate interference with this right on several grounds including public safety, prevention of crime and the protection of the rights of others. 
Such staff have perhaps three or more dozen cases to manage, all different, with managers (and yes, Inspectors) ready to criticise them if they do the wrong thing with any of those cases at various key points. They do not have a very high status within the whole process .... What we found in the Rice case was a lot of evidence of the case manager, and the MAPPA meetings, giving plenty of careful consideration to the issues of treating Rice fairly, and responding accordingly to the solicitor's letters. Usually (but not always, unfortunately) they took the correct view and maintained the restrictions that Rice and his solicitor were complaining about. All this discussion of issues of fairness was all quite well documented. What we then did not find in the records was evidence of sufficient discussion of their continuing assessment and management of Rice's Risk of Harm to others (JCHR 2006: Ev 22).

Three general conclusions on rights discourse, I would argue, can be drawn from the Rice case. First, it needs to be recognised that rights can be fluid and indeterminate, and the meaning of the HRA 1998 will be the subject of ongoing contestation by different constituencies (Whitty et al. 2001). An example of this phenomenon is the ease with which 'human rights' was constructed as the obstacle to effective risk management in the media coverage of the Naomi Bryant murder, and also skilfully used by politicians as camouflage for the administrative failings (and known limitations) within MAPPA. ${ }^{7}$ It is also noteworthy that, despite the clearly-identified failures of risk-based practices, no similar groundswell of criticism developed against risk expertise. Perhaps ironically, the HRA 1998 has taken yet another twist in the context of the Rice case: Liberty, a leading human rights NGO, is now acting for Naomi Bryant's mother in a legal action alleging that her daughter's ECHR Article 2 right to life was violated.

Secondly, in order to understand more fully how the different organisations and actors work together under MAPPA, and how risk and rights discourses relate, the 'dynamics of knowledge production and circulation' require close scrutiny (Valverde et al. 2005: 87). For example, questions need to be asked about which actors use particular knowledges or combinations of knowledges; when and where these knowledges are used; and with what 'legal, social and epistemological effects' (2005: 87). It would be very useful to know, for example, the exact nature and extent of human rights (law) knowledge held by the different MAPPA actors involved in the Rice case. Especially when, as the UK case law on prisoner challenges to parole board decisions clearly demonstrates, there is a longstanding judicial reluctance to become involved in adjudicating on 'expert' risk management of offenders. Whether risk knowledge is legal or non-legal, expert or everyday, or a hybrid of these, will also be an important question to explore. As Valverde et al. (2005: 87) have argued, although the literature on risk and law tends to counterpoise expert knowledge to law and legal reasoning', it is more 'useful to not assume that everything that goes in as "expert witness testimony" is epistemologically homogenous ("science" or "expertise")'. The relationships between risk knowledges and rights knowledges also require scrutiny. In the Rice case, for example, the JCHR Report places emphasis on an understanding of public protection (risk of harm) as an integral part of the HRA 1998 framework

7 See also the political and media linkage of the increase in legal aid for legal representation of prisoners at parole boards (from 425 cases in 2001-02 to 1500 in 2005-06) with the events of the Rice case: 'Legal Aid Bill for Parole Board Challenges Tops £2m' (Guardian, 20 May 2006). 
(rights). In contrast, the Inspectorate places emphasis on the alleged potential for legal knowledge and processes to 'challenge' risk management: '[a]t the point of an oral Parole hearing, as an officer if you are not proposing release you will be cross-examined by a barrister to challenge your assessment, as well as by the Board, but if you are proposing release you will only be questioned by the Board' (JCHR 2006: Ev 22).

Thirdly, and finally, it needs to be emphasised that wider socio-cultural representations and understandings of 'deserving' and 'undeserving' rights-holders will be particularly powerful in the context of serious sex offender management, especially where child victims are involved. Thus, although the ECHR has played an influential role in helping UK government ministers and police forces to preserve the privacy rights of 'paedophiles' - and resist sustained media and public campaigns for US-style open sex offender registers (Hood et al. 2004: 142) - the commitment to individual rights protection in everyday practice may be different. As Kemshall and Maguire revealed in their research on MAPPA, there is an accepted devaluing of the legal rights of some (suspect) offenders:

The notion of offenders' rights took low priority in the thinking of [public protection] panel members; concern was rarely expressed about possible violations of rights to privacy, or of the fundamental distinction between those who are under statutory supervision or control (e.g. on probation or conditional release licence) and those who are not (including those merely suspected of offending). Similarly, although police officers recognized that they had no right to enter the homes even of registered sex offenders, they often deliberately gave them the impression that they did have such rights (2001: 254).

\section{Conclusion}

This analysis of the Rice case aims to counter one-dimensional claims about risk and rights. On the face of it, the case appears to be about dichotomous discourses. However, as highlighted above, the construction, use and representation of different risk knowledges and rights knowledges (by probation officers, the Inspectorate, the JCHR and others), as well as the ways in which these were politicised, indicate a much more complex landscape. My focus on serious sex offenders and the inter-agency structure of MAPPA indicates that there is no uniform quality to risk assessment and management practices (O'Malley 2004). It is also apparent, though, that we know very little about how UK public sector organisations are 'managing' different risk-based and rights-based obligations and goals. The political controversy over 'human rights' in the Rice case reveals the extent to which the HRA 1998 can have both practical and symbolic effects on risk assessment and management. The exact nature, extent and consequences of this relationship between risk and rights remains to be addressed in future legal and criminological scholarship.

\section{REFERENCES}

BBC (2006) 'File on 4: MAPPA', Radio 4 Transcript (7 February).

Bell, Vikki (2002) 'The Vigilant(e) Parent and the Paedophile', Feminist Theory 3: 83-102.

Black, Julia (2005) 'The Emergence of Risk-Based Regulation and the New Public Risk Management in the United Kingdom', Public Law 512-48.

Clements, Luke \& Thomas, Phil (eds) (2005) Human Rights Act: A Success Story? London: Blackwell. 
Falconer, Charles (2007) 'Human Rights and Common Sense', Harry Street Lecture, University of Manchester [http://www.dca.gov.uk/speeches/ministers.htm].

Fisher, Elizabeth (2003) 'The Rise of the Risk Commonwealth and the Challenge for Administrative Law', Public Law 455-78.

Halliday, Simon \& Schmidt, Patrick (eds) (2004) Human Rights Brought Home: Socio-Legal Perspectives on Human Rights in the National Context. Oxford: Hart.

Hannah-Moffat, Kelly (2005) 'Criminogenic Needs and The Transformative Risk Subject', Punishment \& Society 7: 29-51.

Hood, Christopher, Rothstein, Henry \& Baldwin, Robert (2004) The Government of Risk: Understanding Risk Regulation Regimes. Oxford: Oxford University Press.

Hutter, Bridget (2006) 'Risk, Regulation and Management', pp. 202-27 in P. Taylor-Gooby \& J. Zinn (eds), Risk in Social Science. Oxford: Oxford University Press.

Inspectorate of Probation (2006) An Independent Review of Serious Further Offence Case: Anthony Rice. London: Home Office.

Joint Committee on Human Rights (JCHR) (2006) The Human Rights Act, Thirty-Second Report of Session 2005-06. London: Stationery Office.

Kemshall, Hazel (2003) Understanding Risk in Criminal Justice. Maidenhead: Open University Press.

- \& Maguire, Mike (2001) 'Public Protection, Partnership and Risk Penality', Punishment \& Society 3: 237-64.

- Mackenzie, Gill, Wood, Jason, Bailey, Roy \& Yates, Joe (2005) Strengthening Multi-Agency Public Protection Agreements. London: Home Office.

Lester, Anthony \& Pannick, David (2004) Human Rights Law \& Practice. London: LexisNexis.

Levi, Ron (2000) 'The Mutuality of Risk and Community: The Adjudication of Community Notification Statutes', Economy and Society 29: 578-601.

Lupton, Deborah (1999) 'Introduction', pp. 1-11 in D. Lupton (ed), Risk and Sociocultural Theory: New Directions and Perspectives. Cambridge: Cambridge University Press.

Moore, Dawn \& Valverde, Marianne (2000) 'Maidens at Risk: "Date Rape Drugs" and the Formation of Hybrid Risk Knowledges', Economy and Society 29: 514-31.

Murphy, Thérèse \& Whitty, Noel (2007) 'Risk and Human Rights in UK Prison Governance', British Journal of Criminology 47: 798-816.

Mythen, Gabe \& Walklate, Sandra (2006) 'Criminology and Terrorism: Which Thesis? Risk Society or Governmentality?', British Journal of Criminology 46: 379-98.

O’Malley, Pat (2004) Risk, Uncertainty and Government. London: Glasshouse.

Sparks, Richards (2000) 'Risk and Blame in Criminal Justice Controversies: British Press Coverage and Official Discourse on Prison Security (1993-6)', pp. 127-143 in M. Brown \& J. Pratt (eds), Dangerous Offenders: Punishment and Social Order. London: Routledge.

- (2001) 'Degrees of Estrangement: The Cultural Theory of Risk and Comparative Penology', Theoretical Criminology 5: 159-76.

Valverde, Marianne, Levi, Ron \& Moore, Dawn (2005) 'Legal Knowledges of Risk', pp. 86-120 in Law Commission of Canada (ed), Law and Risk. Vancouver: UBC Press.

Whitty, Noel, Murphy, Thérèse \& Livingstone, Stephen (2001) Civil Liberties Law: The Human Rights Act Era. London: Butterworths.

Wood, Joanne (2006) 'Profiling High-Risk Offenders: A Review of 136 Cases', Howard Journal 45: 307-20.

Zedner, Lucia (2006) 'Neither Safe Nor Sound? The Perils and Possibilities of Risk', Canadian Journal of Criminology and Criminal Justice 48: 423-34. 